\title{
JUVENTUDES: UM CLICK, UMA IMAGEM; VÁRIOS CLICKS UMA ETNOGRAFIA
}

\author{
Eliane Cristina Godoy (Ciências Sociais - UEM) \\ Prof. Zuleika de Paula Bueno (Orientadora)
}

\section{RESUMO}

O presente trabalho tem como objetivo geral descrever e analisar as práticas culturais entre os jovens alunos do ensino médio na contemporaneidade, a fim de interpretar a elaboração, a invenção e a criação de suas expressões visuais, estéticas e comunicativas, mediadas pela cultura material: as tecnologias informacionais e comunicacionais (TICs). A tarefa de conhecer as realidades juvenis ocorre por intermédio do estudo de caso etnográfico, com a utilização de fotografias: ora como documento, ora como metodologia. As narrativas orais, imagéticas e escritas são meios expressivos para análise do social. Esta pesquisa tornou-se relevante pela notória presença das TICs, sobretudo, dos celulares no âmbito escolar. Isto tem nos instigado a empreender uma investigação acerca das expressões comunicativas e estéticas dos jovens a partir da análise e interpretação da relação entre as pessoas e os objetos. Consideramos que as coisas não apenas representam as pessoas, mas que as constituem. Os artefatos, os objetos, as TICs fazem parte da condição juvenil e estão conectadas as suas ações cotidianas. As "coisas" são como extensão dos próprios corpos. E o corpo é uma "coisa" importante para as juventudes.

Palavras-chave: Fotografia; Juventude; Tecnologias Informacionais.

\section{CONTEXTO: DE QUE JUVENTUDE ESTAMOS FALANDO?}

O atual cenário social, com todas as suas mudanças e contradições engendra novos processos comunicacionais e informacionais na vida dos sujeitos. Isto nos permite fazer um caminho e um recorte qualitativo para analisar na instituição escolar de nível médio o protagonismo dos jovens, sobretudo as expressões comunicativas e estéticas advindas de novos modos de ser e estar que são construídos a partir das recentes tecnologias informacionais e comunicacionais (TICs). Estas são próprias dos contextos contemporâneos em que tudo se transforma muito rápido. A fluidez, a volatilidade, a efemeridade são adjetivos importantes para a caracterização das subjetividades juvenis, construídas individual e coletivamente, e que fazem parte da escola pública, local "(...) que é majoritariamente o lugar de encontro das trajetórias da maioria" (MARTÍN-BARBERO, 2014).

É nesse contexto e desse lugar de dicotomias, diversidades e conflitos que faço parte há mais de 10 anos, de modo intermitente como professora de sociologia, que surgiu o interesse no debate acerca da juventude, envolvendo as novas tecnologias informacionais e comunicacionais. O interesse nesse tema deve-se, principalmente, à constante, e por vezes ininterrupta, relação entre as pessoas e essas "coisas" apresentadas no âmbito escolar. 


\section{SEMINÁRIO DE PESQUISA EM CIÊNCIAS HUMANAS - SEPECH \\ Humanidades, Estado e desafios didático-científicos \\ Londrina, 27 a 29 de julho de 2016}

O presente trabalho tem como objeto de pesquisa os jovens estudantes do ensino médio da escola pública, especificamente os alunos do Colégio Estadual Vercindes Gerotto Dos Reis, na cidade de Paiçandu, Estado do Paraná. Este colégio oferta a modalidade de ensino regular nos três períodos (matutino, vespertino e noturno), atendendo jovens entre 14 e 18 anos, em média. Esta instituição escolar é composta atualmente por 809 alunos, conforme dados oficiais ${ }^{1}$. O trabalho de campo está sendo realizado desde 2015.

No sentido empregado por Geetz (2014) procuro estar imersa no universo cultural partilhado pelos jovens. Isto porque "(...) a cultura é um contexto, algo dentro do qual eles podem ser descritos de forma inteligível - isto é, descritos com densidade" (GEETZ, 2014, p.10). Analisamos o diálogo estabelecido entre a cultura material (os objetos, os artefatos) e seus significados, bem como a criação de novos processos de expressões comunicativas e de sociabilidades juvenis. As juventudes, categoria central desse trabalho, nem sempre são compreendidas. Quando pensadas são geralmente pela ótica da transitoriedade. Esse tipo caracterização juvenil implica na cristalização de estigmas $^{2}$ sociais, o que inibe a construção de espaços verdadeiramente pensados e construídos para as juventudes contemporâneas. É preciso perceber que “(...) a juventude constitui um processo amplo e complexo da vida do sujeito, (...) e que o jovem não pode ser analisado como um protótipo do adulto" (DAYRELL; MELLO; SOUZA, 2012, p. 164).

São elementos da cultura material os computadores, os celulares, os tablets, por exemplo. Esses passam a ser imprescindíveis para a captação de vários aspectos da vida social. Essa pesquisa justifica-se pela notória presença das TICs no âmbito escolar, sobretudo, do celular. A nossa hipótese é que esses elementos e os processos advindos de seus usos tenham produzido mudanças significativas na vida cotidiana dos jovens.

A tarefa de conhecer as realidades juvenis ocorre por intermédio do estudo de caso etnográfico. O método etnográfico se justifica pelo fato de ser composto por inúmeros procedimentos, sendo "a observação direta (...) sem dúvida a técnica privilegiada para investigar os saberes e as práticas na vida social e reconhecer as ações e as representações coletivas na vida humana" (ROCHA; ECKERT, 2008, p. 2).

Para o desenvolvimento da argumentação e fundamentação teórica desse trabalho, utilizamos como suporte as perspectivas teóricas elaboradas por Marcel Mauss $^{3}$ (2003), bem como os trabalhos enunciados por Daniel Miller ${ }^{4}$ (2013). Ambos versam sobre cultura material, embora em contextos e por perspectivas distintas.

\footnotetext{
${ }^{1}$ Esta informação foi obtida na unidade escolar: via Sistema Estadual de Registro Escolar - Sere. O Sistema Estadual de Registro Escolar é um "Sistema de Informações" desenvolvido com a finalidade principal de racionalizar as atividades burocráticas da secretaria da escola.

${ }^{2} \mathrm{O}$ conceito estigma utilizado neste texto está fundamentado no trabalho de GOLFFMAN (2012). Conforme este autor o sujeito estigmatizado pode ser compreendido como aquele que está inabilitado para aceitação social plena.

${ }^{3}$ Neste trabalho utilizamos para fundamentação teórica dois ensaios de Marcel Mauss. Em um primeiro momento o texto "Ensaio da dádiva: forma e razão da troca nas sociedades arcaicas", extraído originalmente de Année Sociologique, 2a série, v.I [1923-24], 1925. Em um segundo momento, utilizamos o ensaio: "As técnicas do corpo", que foi publicado pela primeira vez no Jounal de Psychologie, v 32, n (3-4), 1935 - Comunicação apresentada à sociedade de psicologia em 17 de maio de 1934.

${ }^{4}$ Os ensaios de Daniel Miller utilizados nesse trabalho foram extraídos do livro "Trecos, troços e coisas: estudos antropológicos sobre a cultura material", 2013.
} 


\section{SEMINÁRIO DE PESQUISA EM CIÊNCIAS HUMANAS - SEPECH \\ Humanidades, Estado e desafios didático-científicos \\ Londrina, 27 a 29 de julho de 2016}

\section{UMA NATIVA PESQUISANDO}

A situação evidenciada com a minha ida a campo foi a seguinte: quando o pesquisador, que também é professor, deixa de ser visto como um colega de trabalho pelos professores e pela direção escolar; quando deixa de ser para seus alunos a figura já conhecida do educador de cada dia, há um enrijecimento entre as fronteiras marcadoras do sujeito que olha, observa e os sujeitos observados.

A professora que a partir de um dado momento posicionou-se como antropóloga, passou a ser imaginada e representada entre os "nativos", ora como aquela que é alienígena, estrangeira e recebedora de memórias; ora como aquela que é inquisidora, delatora a respeito do que se passa no âmbito da educação sistematizada. Neste contexto, houve o que chamo de enrijecimento e endurecimento de fronteiras.

$\mathrm{O}$ endurecimento das fronteiras - a quebra dos diálogos entre a pesquisadora e os pesquisados, bem como a interdição dos espaços antes permitidos para a pesquisadora - possibilitou o estranhamento desta acerca das ações realizadas tanto pelos alunos, como pelos professores. Esse processo contribuiu para a desnaturalização do universo de significações experimentado pela pesquisadora e consequentemente para o empreendimento da análise e interpretação do que é cotidiano e familiar.

Estranhar o que é familiar tornou-se algo necessário, pois conforme afirma DaMatta (1978, p.5) “(...) estranhar alguma regra social familiar e assim descobrir (ou recolocar, como fazem as crianças quando perguntam os 'porquês') o exótico do que está petrificado dentro de nós pela reificação e pelos mecanismos de legitimação". A necessidade de conhecer o que é vivido e experimentado pelos jovens trouxe algumas indagações para essa nativa pesquisadora.

Como é possível imergir e estranhar algo tão familiar e a tão próximo? Esse questionamento me ocorreu a priori e foi tenso, pelo menos até a entrada em campo. Foi preciso revestir o próprio olhar para o que via cotidianamente. Esse processo foi composto por extensas leituras teóricas, várias participações em eventos científicos e por conversas "inacabáveis", tanto com a minha orientadora, como com os colegas e os professores do Programa de Pós Graduação em Ciências Sociais, da Universidade Estadual de Maringá.

A partir do momento em que entrei em campo (como pesquisadora) houve o que chamo de "distanciamento elaborado", isso devido tanto a minha autodenominação como antropóloga, como a utilização de instrumentos de pesquisa, tais como: a máquina fotográfica e o celular - que permitiram não apenas a captura do "real" construído e vivido pelos jovens, mas o retorno as minhas próprias memórias construídas ao longo de $20^{5}$ anos.

$\mathrm{O}$ acesso a essas memórias, a captura de imagens e dos relatos orais contribuíram para a construção narrativa que me aventuro atualmente (essa etnografia). Teoricamente foram os autores Gilberto Velho (1999) e Roberto Da Matta (1978) que forneceram os elementos para a reflexão acerca do que chamo "comportamento antropológico" - o estranhamento do familiar. Isso por que:

\footnotetext{
${ }^{5}$ A escolha desse lugar de observação (o colégio Vercindes Gerotto dos Reis) se deve a minha história com a cidade, com a própria escola e com muitos atores que participaram e que ainda participam desse lugar de "dramatização". Fui aluna nessa instituição entre os anos de 1996 a 1998. Depois retornei em 2009 como colega de trabalho dos meus antigos professores. Atualmente sou efetiva nesse quadro docente.
} 


\section{SEMINÁRIO DE PESQUISA EM CIÊNCIAS HUMANAS - SEPECH \\ Humanidades, Estado e desafios didático-científicos \\ Londrina, 27 a 29 de julho de 2016}

(...) O que sempre vemos e encontramos pode ser familiar, mas não é necessariamente conhecido e o que não vemos e encontramos pode ser exótico, mas até certo ponto, conhecido. No entanto, estamos sempre pressupondo familiaridade e exotismos como fontes de conhecimento ou desconhecimento, respectivamente. (VELLO, 1999, p. 126,).

Os relatos e as imagens coletadas deixam transparecer tanto o campo sendo afetado pela presença da antropóloga, como a pesquisadora sendo afetada por sua incursão etnográfica. $O$ pesquisador e os nativos, ambos são marcados pela experiência etnográfica, e a partir dela vão construindo a realidade vivida por um, e experimentada por outro. A observação e a vivência com eles e entre eles permitiram algumas construções narrativas, cujas origens se devem aos relatos e as imagens capturadas em campo de maneira geralmente fragmentada. Conforme enfatiza Magnani:

(...) a natureza da explicação pela via etnográfica tem como base um insight que permite reorganizar dados percebidos como fragmentários, informações ainda dispersas, indícios soltos, num novo que não é mais o arranjo nativo (mas que parte dele, leva-o em conta, foi suscitado por ele) nem aquele com o qual o pesquisador iniciou a pesquisa. Este novo arranjo carrega a marca de ambos: mais geral do que a explicação nativa, presa as particularidades de seu contexto (...); no entanto, é mais denso que o esquema teórico inicial do pesquisador, pois tem agora o 'concreto vivido'. (MAGNANI, 2002, p 17).

A realidade social juvenil pode ser compreendida de dentro e de perto (MAGNANI, 2002) por uma nativa, que é professora e antropóloga, pois o que é familiar pode ser conhecido antropologicamente. O exercício do olhar para o que há de exótico no que é cotidianamente vivido é uma possibilidade. Podemos encontrar exotismos naquilo que acreditamos conhecer. É na tentativa deste olhar cruzado, desde dentro, como professora e de fora, como antropóloga, sendo dentro e fora ao mesmo tempo, um jogo contínuo entre familiaridades e exotismos; relativizando e estranhando, que busco inventariar e compreender as expressões comunicativas e estéticas, elaboradas e apropriadas pelos jovens alunos do ensino médio.

Diante das múltiplas realidades juvenis e dos vários caminhos que poderia seguir, ficou-me uma indagação: O que observar? Optei então por aquilo que mais me instigava como professora: "O que permite a não dissociação entre as pessoas e essas coisas apresentadas no âmbito escolar?" Esse questionamento tornou-se problema de pesquisa, que posteriormente ganhou corpo e força, especificamente, antes da minha entrada em campo. Foi durante uma aula de sociologia a cerca de cinco anos, quando solicitei a uma aluna que guardasse o aparelho celular ${ }^{6}$. Rapidamente a mesma respondeu-me: "Estou sem créditos professora, não tenho internet!". Ainda assim insisti, e ela guardou o celular. Neste mesmo dia voltei para casa e fiquei refletindo sobre o ocorrido. Pensei: "Se não tem créditos por que estar conectado a este aparelho por tanto tempo?".

\footnotetext{
${ }^{6}$ Existe no Estado do Paraná a lei 18118 de 24 de junho de 2014. Esta lei dispõe sobre a proibição do uso de aparelhos e equipamentos eletrônicos em salas de aula para fins não pedagógicos.
} 


\section{SEMINÁRIO DE PESQUISA EM CIÊNCIAS HUMANAS - SEPECH \\ Humanidades, Estado e desafios didático-científicos \\ Londrina, 27 a 29 de julho de 2016}

A resposta veio algum tempo depois, quando estava cursando (como aluna não regular) uma disciplina do mestrado em Ciências Sociais, intitulada "Cultura, consumo e sociabilidade". Isto ocorreu no ano de 2014, na mesma instituição em que estou vinculada atualmente (UEM) ${ }^{7}$. Nesta disciplina tive a oportunidade de conhecer a professora Doutora Valéria de Assis, que apresentou a turma o livro "Trecos, troços e coisas" (2013), do autor Daniel Miller. Nessa obra, o autor aborda a relevância da cultura material (os trecos, os objetos, os artefatos) para a constituição da pessoa. Foi neste contexto que minhas indagações começaram a tornar-se projeto de pesquisa.

É por intermédio das coisas (dos artefatos) que os sujeitos rememoram sentimentos sensações; constroem relações e elaboram regras e normas sociais (MILLER, 2013). Os trecos fazem das pessoas o que elas são. Desse modo, podemos dizer que o celular enquanto "coisa", pode fazer do jovem o que ele é, ou quem deseja ser.

Retomemos o relato inicial sobre o uso do celular em sala. O celular sem crédito utilizado em sala de aula pela jovem pode ser compreendido se conseguimos "enxergar" o que este carrega: os significados, os valores, as relações construídas dentro e fora da escola. É o aparelho celular, com ou sem internet rompendo e desintegrando as barreiras físicas e normatizadoras, elaboradas e impostas pela escola. Este objeto torna-se mediador, possibilitando tanto as novas formas de comunicação como as novas formas de sociabilidade.

Esse foi o caminho trilhado por mim até a constituição do projeto. "Esta trilha tornou-se estrada" dando origem a essa pesquisa - que se arquiteta tanto pelas lentes nativas como pelas lentas da pesquisadora. Ao mesmo tempo em que observo registro imageticamente o universo investigado, faço minha "participação observante" (ROSISTOLATO, 2013). Narro a minha participação na escola, enquanto nativa e pesquisadora, construindo por intermédio dessa narrativa, uma etnografia da juventude a partir da escola.

\section{A FOTOGRAFIA NA ETNOGRAFIA: GANHOS DE REALIDADE}

A montagem de uma etnografia (ou de um texto etnográfico) assemelha-se muito a de um filme em que o resultado final é sempre uma seleção segundo critérios pré-estabelecidos de uma quantidade muito maior de opções e enfoques. Por esses motivos, os registros fotográficos, fílmicos e de sons deveriam ser vistos não apenas como meios que conduzem a interpretação etnográfica (figurando geralmente na forma de anexos ao texto principal da etnografia), mas serem também objetos de uma auto representação. (SILVA, 2006, p. 59).

$\mathrm{Na}$ prática etnográfica o uso de imagens tem possibilitado ao pesquisador registrar situações e imagens dos seus interlocutores de forma peculiar, principalmente quando se compara com a transcrição efetuada na hora da pesquisa, ou posteriormente nos diários de campo (SILVA, 2006). Não se pretende aqui, contudo, abordar a ineficácia de um ou outro método, não caberia a este trabalho fazê-lo, mesmo porque,

\footnotetext{
${ }^{7}$ Universidade Estadual de Maringá. Programa de pós-graduação em Ciências Sociais.
} 


\section{SEMINÁRIO DE PESQUISA EM CIÊNCIAS HUMANAS - SEPECH \\ Humanidades, Estado e desafios didático-científicos \\ Londrina, 27 a 29 de julho de 2016}

quando se está em campo sabe-se da relevância de várias técnicas para a composição do trabalho final.

A fotografia tem se mostrado uma excelente aliada e um importante recurso para a captura de imagens. As imagens coletadas representam por sua vez as realidades da vida cotidiana dos jovens, dentro e fora do espaço escolar. É através das fotografias que procuramos inventariar as formas pelas quais os jovens se expressam: como se colocam na presença do outro (s), como se comunicam entre si e como se relacionam com as TICs.

O método etnográfico, com a utilização das fotografias tornou-se possível justamente devido à familiaridade com que os jovens lidam com essas tecnologias. Essa proximidade possibilitou um processo de investigação acerca das narrativas imagéticas, orais e escritas que se fazem presentes nesse espaço. Fotografei praticamente todos os dias. Conversei com os jovens de forma frequente, tanto pessoalmente, como pelos grupos de WhatsApp. Os muitos clicks e as conversas permitiram um acumulo de narrativas imagéticas e orais que sobreposta à teoria, anteriormente aprendidas, possibilitou o tecer dessa etnografia: um trabalho artesanal que se constitui dia após dia. A elaboração dessa etnografia se dá pelo ato contínuo de releituras, tanto dos diários de campo, como das imagens construídas e capturadas pelas lentes fotográficas.

O pesquisador seleciona imagens e relatos que vão compondo a etnografia, que se estrutura a partir da realidade construída e vivenciada por ambos - pesquisador e nativos. As imagens capturadas pela lente do pesquisador (ou a dos próprios nativos) de algum modo direciona o olhar. O pesquisador seleciona o que deseja ver ou ouvir, seja nos momentos em que os fatos se desenvolvem, seja posteriormente quando seleciona quais partes desses registros, imagéticos ou não, serão significativos para a sua interpretação (SILVA, 2006).

A realidade deve ser compreendida como uma construção social (BERGER; LUCKMANN, 2004) onde cada sujeito ou grupo elabora sua "realidade" considerando os diálogos, as situações e os contextos em que estão inseridos. É de acordo com esses elementos que a fotografia passa a ser é utilizada neste trabalho. A imagem fotográfica é observada como uma possibilidade perceptível de registrar os ganhos da realidade construída e modificada pelos sujeitos, neste caso, os alunos. Por intermédio da fotografia torna-se possível ver e rever as ações capturadas, pois “(...) o que a fotografia reproduz ao infinito só acorreu uma vez: ela repete mecanicamente o que nunca mais poderá repetir-se existencialmente" (BARTHES, 2012, p. 15-16).

Tanto a fotografia como outras técnicas de investigação conhecidas e consagradas devem ser pensadas com certa relatividade, pois, em cada contexto, para cada trabalho, os métodos precisam ser testados, observados e contrapostos se necessário, para que possamos chegar o mais próximo possível da realidade construída pelo grupo pesquisado, pois, tomar a imagem fotográfica como documento social em termos absolutos envolvem as mesmas dificuldades que há quando se toma palavra falada, o depoimento ou a entrevista (MARTINS, 2008, p. 11).

\subsection{Os primeiros clicks: a câmara e o celular nas mãos dos nativos}

Durante as primeiras observações realizadas na escola utilizamos como recurso para a coleta de dados às narrativas (imagéticas e escritas) produzidas nos trabalhos realizados pelos alunos dos terceiros anos. Esses trabalhos foram solicitados pela 


\section{SEMINÁRIO DE PESQUISA EM CIÊNCIAS HUMANAS - SEPECH \\ Humanidades, Estado e desafios didático-científicos \\ Londrina, 27 a 29 de julho de 2016}

professora (pesquisadora) e desenvolvidos pelos alunos com a utilização de imagens fotográficas, que foram em sua maioria capturadas pelos próprios sujeitos em outros contextos. O principal objetivo dessa atividade era conseguir uma representação do que é ser jovem a partir da perspectiva e da lente do "nativo".

Para esta atividade cada aluno responsabilizou-se em trazer uma ou mais fotografias, que em sala de aula foram utilizadas para a representação de si. As imagens escolhidas pelos nativos foram submetidas a uma análise explicativa e descritiva, efetuada pelo próprio jovem, acerca do questionamento apresentado anteriormente pela professora: "o que é ser jovem?". Essa primeira etapa da pesquisa foi realizada nos períodos matutino e vespertino com os alunos dos $3^{\circ}$ anos (A, B e D) no ano de 2015. Ao todo foram coletados 90 trabalhos, dos quais 10 não havia imagens. Recolhemos mais 100 fotografias. Dessas imagens e desses relatos resultaram as primeiras análises e interpretações sobre o universo nativo.

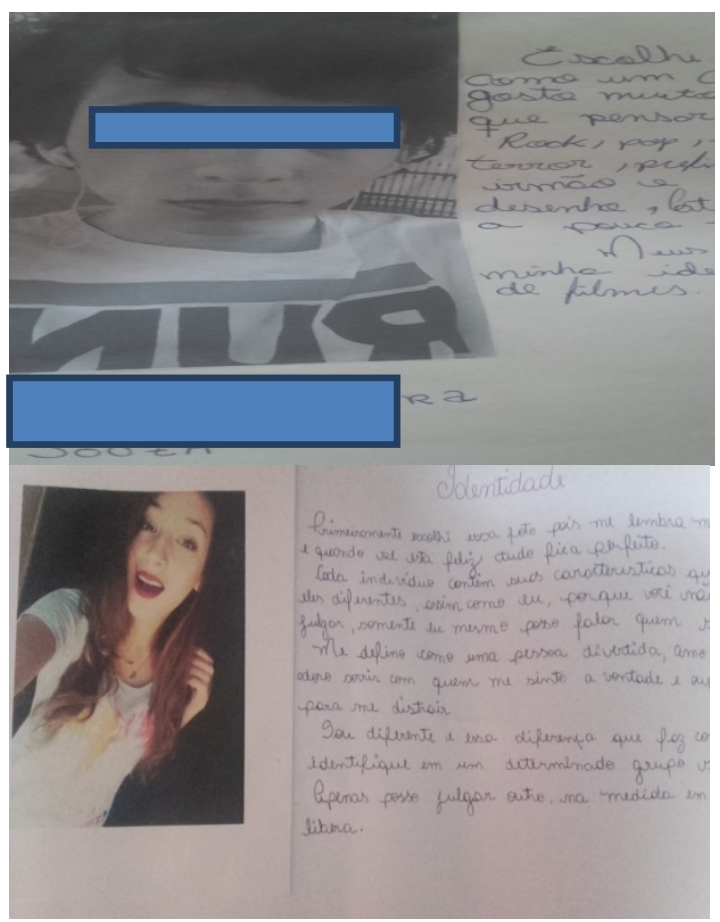

Figura 1 - O que é ser jovem? A perspectiva do nativo.

Figura 2 - O que é ser jovem? A perspectiva da nativa. Fotografia autor - arquivo pessoal do aluno, 2015.

Fonte: Fotografia autor - arquivo pessoal da aluna, 2015.

Essa etnografia se constitui na elaboração do real a partir da perspectiva e da lente do nativo, bem como da interpretação que o pesquisador faz dessas realidades construídas pelos jovens na mediação com as TICs. Os fenômenos são capturados pelos instrumentos: celular ou câmara fotográfica. Das imagens coletadas e analisadas exponho neste artigo para efeito de representação dos ganhos de realidades apenas duas fotografias (figura 1 e 2).

As imagens coletadas nesses trabalhos e posteriormente analisadas apresentavam elementos da cultura material, sobretudo, os celulares, que foram em certa medida responsáveis pela captura das imagens utilizadas no trabalho sobre 


\section{SEMINÁRIO DE PESQUISA EM CIÊNCIAS HUMANAS - SEPECH \\ Humanidades, Estado e desafios didático-científicos \\ Londrina, 27 a 29 de julho de 2016}

representação si. Apesar disso, as TICs foram apenas timidamente mencionadas. Desse modo, quando foram indagados sobre o processo de obtenção das imagens para o trabalho, ou porque não haviam trazido o material solicitado - as fotografias. Responderam: "Professora não força! hoje ninguém revela fotografias".

Por intermédio das conversas, das observações e dos registros imagéticos obtidos, evidenciou-se o aparecimento de uma prática social, que traz como referencial a mudança de costumes. Assim, as imagens que outrora eram capturadas por máquinas fotográficas de modo ritualístico, em lugares, com pessoas e posições corporais delimitadas e repetidas, e que acabavam destinando-se a um espaço reservado e quase mágico da casa: a caixa de recordações da família. Vão aos poucos cedendo lugares para outras práticas sociais. A velha caixa de recordações - ou simplesmente, a caixa de sapato, ou de camisa - começam a dar lugar a outros objetos: os celulares, os computadores; ou ainda, a outros espaços: as mídias sociais ${ }^{8}$.

Por intermédio dos diálogos com os nativos observei que muitas famílias deixaram de revelar fotografias. Segundo eles, isso se deve à praticidade oferecida pelas novas tecnologias, que permitem o armazenamento de uma grande quantidade de imagens em pastas organizadas por títulos e datas. As imagens fotográficas são atualmente capturadas em praticamente todos os espaços, quebrando tabus e permitindo aos sujeitos se expressarem de maneira performativa: cada um atribui a si mesmo uma multiplicidade de gestos, expressões faciais e corporais. As novas tecnologias facilitam tanto a visualização rápida, como também o descarte ou a agência das mesmas para a publicação nas mídias sociais (Facebook e Instagram). Isso explica em parte o fato de alguns alunos não utilizarem imagens impressas para realização desse primeiro trabalho.

Observei que o celular foi constantemente utilizado como elo entre o "mundo externo" e a escola. A evidência do elo. Durante o desenvolvimento dessa primeira atividade e por intermédio do celular, os alunos transferiram as fotografias de um aparelho para outros, utilizando o Bluetooth $^{9}$. Na sequência utilizaram o meu computador para fazerem o download das imagens, que posteriormente seriam empregadas na representação de si. Depois de baixarem as imagens para o computador, transferiram-nas para um pen drive. Em seguida, dirigiram-se até a biblioteca da escola onde realizaram as impressões das imagens fotográficas, que deram origem aos trabalhos produzidos em sala de aula. Utilizaram as TICs em todo o processo, tanto para a obtenção das imagens, como para a execução do trabalho. Todavia, não falaram delas como representação do que é ser jovem. Essa situação deixou algumas indagações, abrindo questionamentos que dialogaram diretamente com meu problema de pesquisa: de que os elementos da cultura material (as TICs) tenham trazido mudanças significativas para a vida cotidiana dos jovens.

Por meio da avaliação desses processos foi possível desenvolver as primeiras representações sobre o mundo nativo, seja por uma lente dupla: olhar nativo (professor), mais olhar antropológico (conhecimentos acadêmicos). Seja por uma lente tripla: olhar

\footnotetext{
${ }^{8}$ Mídias sociais: essa expressão está sendo utilizada no sentido empregado por Daniel Miller no curso de extensão EAD: Por que Postamos (2016), promovido pela universidade de London. De acordo com o curso ministrado por Daniel Miller as mídias sociais podem ser compreendidas como os suportes: Facebook, Twitter, Instagram e WhatsApp.

${ }^{9}$ Bluetooth é o nome de uma tecnologia de comunicação sem fios (wireless) que interliga e permite a transmissão de dados entre computadores, telefones celulares, câmeras digitais e outros dispositivos através de ondas de rádio.
} 


\section{SEMINÁRIO DE PESQUISA EM CIÊNCIAS HUMANAS - SEPECH \\ Humanidades, Estado e desafios didático-científicos \\ Londrina, 27 a 29 de julho de 2016}

nativo (professor), agregado ao olhar do pesquisador (conhecimentos acadêmicos), que observa a perspectiva nativa através da lente fotográfica - recurso responsável pela captura de ganhos de realidade.

A indagação sobre a não dissociação entre as pessoas e as coisas apresentadas na escola tornou-se justificável devido ao desejo de saber, por que o celular, ou as outras tecnologias, enquanto elementos da cultura material não haviam sido mencionados pelos nativos no trabalho realizado com as fotografias? Quando indaguei os jovens a respeito dessa contradição, indicaram como resposta: "Professora isso é tão "normal" que imaginamos que não tinha necessidade em dizer, pois você já sabe que é importante, que faz parte das nossas vidas, e pronto!".

Ainda de modo provisório, visto que a pesquisa está em andamento, arrisco dizer que estas "coisas", as TICs estão de tal modo conectado aos jovens, perfazendo a vinculação entre eles (e digo, também entre nós), que são como extensão dos próprios corpos. As observações em campo vêm aos poucos delineando que as TICs, sobretudo, os celulares fazem diferença nos processos de sociabilidade e de comunicação juvenil. Estas são consideradas pelos jovens como facilitadores de ações e práticas cotidianas envolvendo as relações afetivas, de trabalho, de consumo e também de aprendizagem.

Podemos considerar que enquanto elemento da cultura material, as tecnologias não estão separadas dos valores, dos significados, a elas conectados. Conforme as abordagens efetuadas por MAUSS $(2003$, p. 212) as coisas, os objetos tem alma, valor e significado. E, é nestes processos em que as coisas e as pessoas, o local e suas especificidades, dialogam com o mundo.

\section{CONSIDERAÇÕES FINAIS}

A pesquisa etnográfica desenvolvida entre os jovens têm até o presente momento permitido registros que evidenciam o diálogo destes com as TICs - as coisas apresentadas na escola. A compreensão acerca do universo nativo se constitui por um artesanato intelectual: uma construção engenhosa e cotidiana, na qual se sobrepõem teoria e vivência, para a elaboração de uma narrativa etnográfica, que se constitui a partir das narrativas orais e iconográficas, coletadas em campo por uma pesquisadora nativa.

Essa etnografia desenvolve-se por intermédio de um estudo de caso etnográfico: com a participação observante, e com a técnica de captura e análise das narrativas imagéticas, contidas nas fotografias. A utilização das fotografias tem possibilitado uma análise da realidade social juvenil de maneira distinta. Visto que tanto as imagens, como as TICs são "coisas" relevantes para a constituição das juventudes.

As novas tecnologias fazem parte da condição juvenil, das suas ações cotidianas. É por intermédio delas que os jovens estabelecem vínculos, constroem relações. As TICs são como extensão dos próprios corpos, pois "as máquinas podem ser dispositivos protéticos, componentes íntimos, amigáveis eus" (HAROWAY, 2009, p.92). É através do corpo e na utilização da cultura material que esses jovens constituem o social.

As fotografias são tomadas como construções sociais, produzidas e experimentadas pelas juventudes. Essas imagens contribuem para a descrição e para interpretação acerca dos fenômenos apresentados na escola, pois produzem ganhos de 


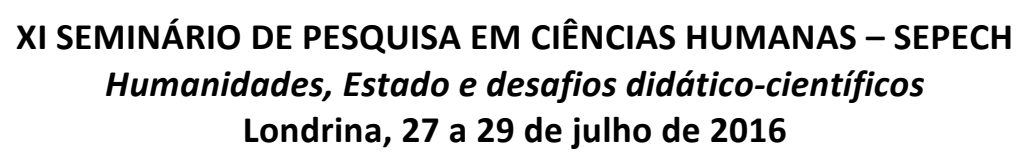

realidade. Essas iconografias podem ser adotadas como descrições "densas" (GEETZ, 2014) acerca dos fatos vivenciados pelos atores sociais, sejam eles, coisas ou pessoas ou ambos em relação.

\section{REFERÊNCIAS}

BERGER, Peter; Luckmann, Thomas. A Construção social da realidade. Petrópolis, Vozes, 2004.

BARTHES, Roland. A câmara clara: notas sobre a fotografia. [ed. especial]. Rio de Janeiro: Nova Fronteira, 2012.

DA MATTA, R. O ofício do etnólogo ou como ter "Anthropological Blues". In: NUNES, E. (org.). A Aventura Sociológica. Rio de Janeiro: Zahar, 1978.

DAYRELL, Juarez; MELO, L. C. M.; SOUZA, G. S. Escola e juventude: uma relação possível. Paidéia (Belo Horizonte), v. 12, p. 161-186, 2012. Disponível em

http://www.fumec.br/revistas/paideia/article/view/1 584 acesso em: 18 de dezembro de 2015.

GEETZ, Clifford. A interpretação das culturas. 1ª ed. Rio de Janeiro: LTC, 2014.

GOFFMAN, Erving. Estigma: Notas sobre a Manipulação da Identidade Deteriorada. 4, ed. Rio de Janeiro: LTC, 2012.

HARAWAY, Donna. Manifesto Ciborgue: Ciência, tecnologia feminismo-socialista do final do século XX. In: TADEU, Tomaz (Org.). Antropologia Ciborgue: as vertigens do pós-humano. 2. ed. Belo Horizonte: Autêntica Editora, 2009.

MAGNANI, José Guilherme Cantor. De perto e de dentro: notas para uma etnografia urbana. Revista Brasileira de Ciências Sociais, vol. 17, n. 49. São Paulo, junho de 2002. Disponível em http://www.scielo.br/pdf/rbcsoc/v17n49/a02v1749.pdf

MARTÍN-BARBERO, Jesús. A comunicação na educação. São Paulo: Contexto, 2014.

MARTINS, José de Souza. Sociologia da fotografia e da imagem. São Paulo: Contexto, 2008.

MAUSS, Marcel. Ensaio sobre a dádiva: forma e razão das trocas nas sociedades arcaicas. In: Sociologia e Antropologia. São Paulo: Cosac Naify, 2003.

MILLER, Daniel. Trecos, troços e coisas: estudos antropológicos sobre a cultura material. Rio de Janeiro: Zahar, 2013. 


\section{SEMINÁRIO DE PESQUISA EM CIÊNCIAS HUMANAS - SEPECH \\ Humanidades, Estado e desafios didático-científicos \\ Londrina, 27 a 29 de julho de 2016}

PARANÁ. Casa civil sistema estadual de legislação. Dispõe sobre a proibição do uso de aparelhos/equipamentos eletrônicos em salas de aula para fins não pedagógicos no Estado do Paraná. Disponível em http://www.legislacao.pr.gov.br/legislacao/listarAtosAno.do?action=exibir\&codAto $=12$ 3359 acesso em: 20 de Fev. de 2016.

PEREIRA, Alexandre Barbosa. "A maior Zueira": experiências juvenis na periferia de são Paulo. 2010. Tese de doutorado, Universidade de São Paulo, 2010.

ROCHA, Ana Luiza da; ECKERT, Cornélia. Etnografia saberes e práticas. In: (Orgs) PINTO, Célia Regina Jardim; GUAZZELLI, César Augustos Barcellos. Ciências Humanas: pesquisas e métodos. Porto Alegre: editora da universidade, 2008.

ROSISTOLATO, Rodrigo. "Você sabe como é, eles não estão acostumados com antropólogos!": uma análise etnográfica da formação de professores. Pro-Posições, v. 24, n. 2 (71), p. 41-54, maio/ago. 2013. Disponível emhttp://www.scielo.br/pdf/pp/v24n2/v24n2a04.pdf acesso em: 25 de novembro de 2015.

SILVA. Wagner Gonçalves da. O antropólogo e sua magia: trabalho de campo e texto etnográfico nas pesquisas antropológicas sobre religiões afro-brasileiras. São Paulo: Editora da universidade do Estado de São Paulo, 2006.

(BERGER; LUCKMANN, 2004).

VELHO, Gilberto. Individualismo e cultura: notas para uma antropologia da sociedade contemporânea. $6^{\text {a }}$ ed. Rio de Janeiro: Jorge Zahar, 1999. 